\title{
$N$-Acetyl-D-galactosamine specific lectin of Eikenella corrodens induces intercellular adhesion molecule-1 (ICAM-1) production by human oral epithelial cells
}

\author{
MASAYOSHI YAMADA, HIDEAKI NAKAE, HIROMICHI YUMOTO, CHIHIRO SHINOHARA, \\ SHIGEYUKI EBISU* and TAKASHI MATSUO
}

Department of Conservative Dentistry, Tokushima University School of Dentistry, Tokushima $770-8504$ and * Department of Restorative Dentistry and Endodontology, Osaka University Graduate School of Dentistry, Osaka 565-0871, Japan

\begin{abstract}
During the acute inflammatory response in periodontitis, gingival epithelial cells are considered to play important roles in the recruitment of inflammatory cells to the site of infection through the secretion of chemokines. However, little is known about the expression of molecules that are involved in the interaction between the epithelium and neutrophils following bacterial attachment. Earlier work reported that periodontopathogenic Eikenella corrodens strain 1073 up-regulated the expression and secretion of chemokines such as interleukin-8 (IL-8) from KB cells (a human oral epithelial cell line derived from a human oral epidermoid carcinoma). To elucidate the mechanism of the transmigration of neutrophils through the epithelium, the present study investigated the expression of adhesion molecules on $\mathrm{KB}$ cells in response to $E$. corrodens attachment. Adhesion molecule gene expression was assessed by RT-PCR and adhesion proteins expressed on KB cell surfaces were determined by cell-based ELISA and FACS. In RTPCR, ICAM-1 mRNA levels were significantly increased within $1 \mathrm{~h}$ in response to exposure to $E$. corrodens and continued to increase over the 12-h period of study. In ELISA, increased surface ICAM-1 expression was paralleled by increased ICAM-1 mRNA levels. Furthermore, the increases in ICAM-1 expression on epithelial cells infected with $E$. corrodens were observed to be due to the $N$-acetyl-D-galactosamine (GalNAc) specific bacterial lectin-like substance of $E$. corrodens (EcLS), which was one of the adhesins of $E$. corrodens. This is the first study to report that a bacterial lectinlike substance increased the expression of ICAM-1 on gingival epithelial cells.
\end{abstract}

\section{Introduction}

Periodontitis is the inflammatory response in gingival and connective tissue elicited by bacterial colonisation in periodontal pockets. In this response, pocket epithelial cells may be the first cells of defence against periodontopathic bacteria and may be the primary source of the pro-inflammatory and inflammatory cytokine signals for initiation of the inflammatory response to periodontal pathogens. The initiation of periodontitis is often characterised by an influx of

Received 27 March 2002; accepted 1 June 2002.

Corresponding author: Dr H. Nakae (e-mail: nakae@dent. dent.tokushima-u.ac.jp). neutrophils into the periodontal tissues across the epithelium [1]. When neutrophils transmigrate in large numbers, the resulting epithelial discontinuities are thought to represent precursor lesions for erosions and, subsequently, mucosal ulcers that develop in certain inflammatory periodontal diseases [2].

In the transmigration of neutrophils through gingival epithelial cells, cell-cell interactions play an important and probably central role. Tonetti et al. [3] reported the presence of high densities of ICAM-1 and interleukin- 8 (IL-8)-positive cells in the most superficial layers of the junctional epithelium in periodontal pockets in periodontitis. Moreover, several studies [4-7] reported that the levels of ICAM-1 at the junctional epithelium were 
correlated with the intensity of the clinical conditions. These findings suggest that expression of cell adhesion molecules on gingival epithelial cells may participate in neutrophil homing and epithelial cell adhesion in periodontopathic bacteria-associated periodontal inflammation. Therefore, in periodontitis the production of chemokines and adhesion molecules could provide a means of recruiting and retaining inflammatory cells within the gingival epithelial layer, contributing to periodontopathic bacteria-mediated tissue injury.

Eikenella corrodens, a facultative gram-negative anaerobic rod, is found predominantly in subgingival plaque in patients with advanced periodontitis and may also cause extra-oral infections including abscesses, endocarditis, osteomyelitis, keratitis, conjunctivitis and cellulitis [8-11]. Earlier studies reported that $E$. corrodens 1073 has a cell-associated $N$-acetyl-Dgalactosamine (GalNAc) specific lectin-like substance (EcLS) that mediates its adherence to various host tissue cell surfaces and oral bacteria [12-16]. It was also found that EcLS stimulates the proliferation of murine B cells [17]. EcLS is a large molecule and is composed of several components including 25-, 45and $300-\mathrm{kDa}$ proteins $[18,19]$. Moreover, it has been shown that soluble products from E. corrodens 1073 induce the secretion and the expression of IL- 8 by a human oral epidermoid carcinoma cell line (KB) [20, 21].

To elucidate further the mechanisms of the transepithelial migration of neutrophils the present study investigated whether E. corrodens 1073 induces the expression of ICAM-1, one of the key adhesion molecules in the transepithelial migration of neutrophils, on gingival epithelial cells after infection with $E$. corrodens. Furthermore, the properties of the ICAM-1 induction factors from $E$. corrodens were characterised.

\section{Materials and methods}

\section{Bacteria and growth conditions}

E. corrodens 1073 was provided by S. S. Socransky (The Forsyth Institute, Boston, MA, USA) and was cultured at $37^{\circ} \mathrm{C}$ in tryptic soy broth containing $\mathrm{KNO}_{3}$ $2 \mathrm{mg} / \mathrm{ml}$ and haemin $5 \mu \mathrm{g} / \mathrm{ml}$ under anaerobic conditions $\left(\mathrm{N}_{2} 95 \%, \mathrm{CO}_{2} 5 \%\right)$.

\section{Cell culture}

The KB cell line (derived from a human oral epidermoid carcinoma) was provided by $\mathrm{T}$. Okamoto (Hiroshima University School of Dentistry, Hiroshima, Japan). The KB cells were cultured in Dulbecco's Modified Eagle's Medium (DMEM; Gibco, Grand Island, NY, USA) supplemented with $2 \mathrm{mM}$ L-glutamine, fetal bovine serum (FBS; JRH Biosciences, Lenexa, KA, USA) $10 \% \mathrm{v} / \mathrm{v}$, penicillin $50 \mathrm{IU} / \mathrm{ml}$ and streptomycin $50 \mu \mathrm{g} / \mathrm{ml}$ at $37^{\circ} \mathrm{C}$ in a water-saturated atmosphere of $\mathrm{CO}_{2} 5 \%$ in air.

\section{Infection of $K B$ cells}

Approximately $10^{5} \mathrm{~KB}$ cells in DMEM were seeded into wells of 24-well tissue culture plates and incubated until confluent monolayers developed. The bacteria were pelleted by centrifugation, washed twice in phosphated-buffered saline (PBS, pH 7.2), and suspended in DMEM without serum and antibiotics at a concentration of $\left(1.0 \times 10^{8}\right)-\left(2.0 \times 10^{8}\right) \mathrm{cfu} / \mathrm{ml}$. The bacterial concentrations were determined spectrophotometrically according to standard curves. KB cell layers were washed three times with Hanks's Balanced Salts Solution (Gibco), inoculated with $500 \mu \mathrm{l}$ of the microbial suspension, and incubated at $37^{\circ} \mathrm{C}$. As a control, interferon(IFN)- $\gamma$ (Boehringer Mannheim, Tokyo, Japan) $40 \mathrm{ng} / \mathrm{ml}$ was added. For the kinetics studies, cells were incubated for $0.5,1,4,6$ and $12 \mathrm{~h}$. At the end of these incubation periods, the culture medium was collected and centrifuged, and the supernate was stored at $-20^{\circ} \mathrm{C}$ until assayed. RNA was extracted immediately from the cells as described below.

\section{RNA extraction and cDNA preparation}

Total RNA was extracted from KB cells, prepared as described above, with a Catrimox-14 (Iowa Biotechnology, Coralville, IA, USA) according to the manufacturer's instructions. RT-PCR was performed as described previously [22]. The following primers were used to amplify a fragment of ICAM-1 from cDNA: 5'-CGTGCCGCACTGAACTGGAC-3' (sense) and 5'CCTCACACTTCACTGTCACCT-3' (antisense). After pre-denaturation for $2 \mathrm{~min}$ at $94^{\circ} \mathrm{C}$, the PCR conditions for ICAM-1 were as follows: denaturation at $94^{\circ} \mathrm{C}$ for $1 \mathrm{~min}$, annealing at $60^{\circ} \mathrm{C}$ for $1 \mathrm{~min}$ and extension at $72^{\circ} \mathrm{C}$ for $1 \mathrm{~min}$. The number of PCR cycles was 36 to ensure detection of low-abundance mRNA. The GAPDH housekeeping gene transcript was used as the control. A sample of each amplified product was subjected to electrophoresis in an agarose $1.5 \%$ gel (TaKaRa, Shiga, Japan), stained with ethidium bromide and visualised by UV illumination.

For negative controls, the Moloney murine leukaemia virus RT was omitted from the cDNA synthesis mixture to ensure amplification from genomic DNA.

The amount of ICAM-1 mRNA, compared with that of GAPDH mRNA in the controls, was semi-quantified by scanning densitometry of the gel with NIH Image 1.62, as reported by Darveau et al. [23].

\section{Assay of sICAM-1 release}

$\mathrm{KB}$ cells were infected with $E$. corrodens for $0.5,1,4$, 6 and $12 \mathrm{~h}$ as described above. At each time point, 
samples of cell culture supernate were removed and the concentration of sICAM-1 was measured by ELISA. A commercially available ELISA kit (Biosource, Camerillo, CA, USA) for the quantification of sICAM-1 was used as described in the manufacturer's instructions.

\section{Cell-based ELISA}

$\mathrm{KB}$ cells $\left(5 \times 10^{4}\right.$ cells/well $)$ were seeded into 96-well plates and cultured for $48 \mathrm{~h}$. Then, KB cells were cultured with E. corrodens cells or EcLS for $10 \mathrm{~h}$ in the presence or absence of GalNAc. After incubation, $\mathrm{KB}$ cells were washed with PBS and were fixed with paraformaldehyde $4 \%$ in PBS. Then KB cells were blocked with bovine serum albumin (BSA) 2\% for $1 \mathrm{~h}$. $\mathrm{KB}$ cells were incubated for $30 \mathrm{~min}$ with anti-human ICAM-1 monoclonal antibody (MAb) (Ancell, Bayport, $\mathrm{MN})$ at a dilution of 1 in 200. After washing twice, cells were incubated for $40 \mathrm{~min}$ with biotin-conjugated goat anti-mouse IgG (DAKO, Tokyo, Japan) at a dilution of 1 in 50 and incubated with avidinconjugated horseradish peroxidase for $30 \mathrm{~min}$. The assay was developed by addition of TMB peroxidase EIA substrate (BioRad, Tokyo, Japan).

\section{Flow cytometric analysis}

Monolayers of $\mathrm{KB}$ cells were detached by incubation with trypsin $0.25 \%$ and EDTA $0.25 \%$ in calcium- and magnesium-free PBS ( $\mathrm{pH}$ 7.2). For single-label flow cytometric analysis of ICAM-1 expression, $2 \times 10^{5}$ cells $/ \mathrm{ml}$ were incubated for $30 \mathrm{~min}$ on ice with $2.5 \mu \mathrm{l}$ of anti-human ICAM-1 MAb in a total volume of $500 \mu \mathrm{l}$ of PBS containing $0.05 \mathrm{mM}$ EDTA, BSA $0.1 \%$ and FBS $0.05 \%$. After washing twice, cells were incubated for $30 \mathrm{~min}$ on ice with $500 \mu \mathrm{l}$ of a dilution (1 in 100) of fluorescein isothiocyanate (FITC)-conjugated goat anti-mouse IgG1 (DAKO). Cells were washed twice with PBS then the immunofluorescence of the FITC single label was measured with a flow cytometer (Coulter XL-MCL, Coulter Electronic, Hialeah, FL, USA).

\section{Neutrophil adhesion assay}

$\mathrm{KB}$ cells were seeded at a concentration of $2 \times 10^{5}$ cells $/ \mathrm{ml}$ into 24-well culture plates and stimulated by E. corrodens for $10 \mathrm{~h}$ in the presence or absence of $50 \mathrm{mM}$ GalNAc. As a positive control, parallel cultures were stimulated for the same duration with IFN- $\gamma$ $40 \mathrm{ng} / \mathrm{ml}$. After incubation for $10 \mathrm{~h}$, medium containing bacteria or IFN- $\gamma$ was removed and $\mathrm{KB}$ cells were washed twice with HBSS. For the neutrophil adhesion assay, neutrophils were resuspended in DMEM at a concentration of $1.0 \times 10^{6}$ cells $/ \mathrm{ml}$. Neutrophils were added to confluent $\mathrm{KB}$ cell monolayers infected with $E$. corrodens for $10 \mathrm{~h}$. The cultures were centrifuged at room temperature for $5 \mathrm{~min}$ at $50 \mathrm{~g}$. Cultures were incubated for $30 \mathrm{~min}$ at $37^{\circ} \mathrm{C}$, after which monolayers were gently washed three times with PBS to remove non-adherent neutrophils. Neutrophil adherence was quantified by assaying myeloperoxidase activity in the adherent neutrophils by the method of Huang et al. [22]. For myeloperoxidase assays, $450 \mu \mathrm{l}$ of PBS containing Triton X-100 $0.5 \%$ were added to the epithelial cell/neutrophil co-cultures, followed by the addition of $50 \mu \mathrm{l}$ of $1.0 \mathrm{M}$ citrate buffer, $\mathrm{pH} 4.2$. Lysates were centrifuged to remove debris, and enzymic activity was determined by adding a sample of the cell lysates to a solution containing $1 \mathrm{mM}$ ABTS (2,2' -azio-di-\{3-ethyl $\}$ dithiazoline-6-sulphonic acid), $10 \mathrm{mM} \mathrm{H} \mathrm{H}_{2} \mathrm{O}_{2}$ in $100 \mathrm{mM}$ citrate buffer ( $\mathrm{pH}$ 4.2). Absorbance was determined with a microplate reader (BioRad) at $405 \mathrm{~nm}$.

\section{Purification of EcLS}

EcLS was purified from E. corrodens 1073 cells on the basis of its haemagglutination activity [16]. E. corrodens 1073 cells were sonicated in the presence of Triton X-100 $0.1 \%$ and $10 \mathrm{mM}$ EDTA. The supernate was collected and dialysed against $\mathrm{CaCl}_{2} \quad 0.1 \%$ (PBS$\mathrm{TC})$. The dialysate was applied to a galactosamine affinity column (Pierce, Rockford, IL, USA) and eluted with PBS-TC containing $10 \mathrm{mM}$ GalNAc. The fraction eluted with $10 \mathrm{mM}$ GalNAc was precipitated with ethanol and the precipitate was dialysed against distilled water and lyophilised.

\section{Statistical analysis}

All statistical analyses were performed by the unpaired Student's $t$ test. Differences in the data were considered significant when the probability value was $<5 \%$ $(\mathrm{p}<0.05)$.

\section{Results}

Effect of E. corrodens on ICAM-1-specific $m R N A$ in $K B$ cells

To assess the specific induction of ICAM-1 at the mRNA level, RT-PCR was performed with the RNA isolated from $\mathrm{KB}$ cells after bacterial stimulation for $8 \mathrm{~h}$, and the amounts of ICAM- 1 mRNA were semiquantified by scanning densitometry of the gel with the NIH Image 1.62 analysis software program, as reported by Darveau et al. [23]. As shown in Fig. 1, infection of $\mathrm{KB}$ cells with $E$. corrodens 1073 significantly increased the level of ICAM-1-specific mRNA compared with those from uninfected control cells. IFN- $\gamma$ was used as a positive control.

Time-course analysis of ICAM-1 mRNA expression following infection with E. corrodens

A time-course analysis of ICAM-1 mRNA expression by $\mathrm{KB}$ cells is shown in Fig. 2. The expression of ICAM-1 mRNA levels increased within $30 \mathrm{~min}$ after 

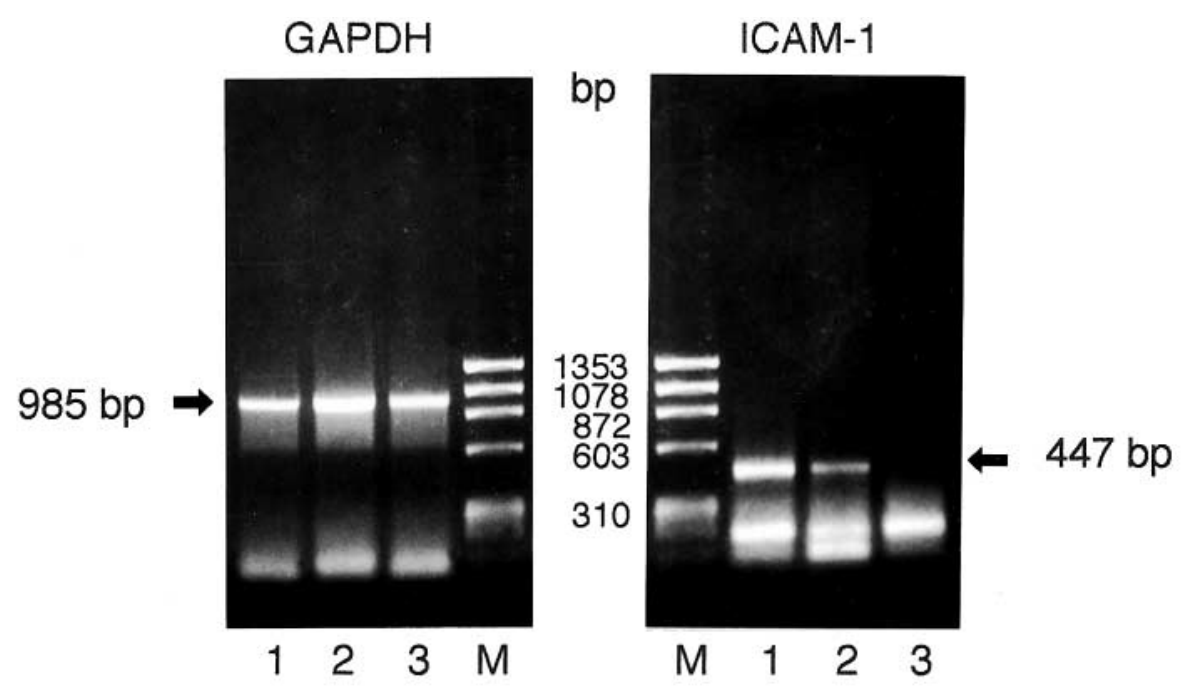

Fig. 1. ICAM-1 mRNA expression by KB cells after stimulation with E. corrodens 1073. RNA was isolated from KB cells after bacterial stimulation for $10 \mathrm{~h}$. cDNA synthesis and RT-PCR were performed as described in Materials and methods. The GAPDH housekeeping gene was used as the control. Lane 1, positive control (IFN- $\gamma$ ); 2, E. corrodens 1073; 3, control (medium alone); M, markers. The amounts of ICAM-1 mRNA, compared with those of GAPDH mRNA in the controls, were semi-quantified by scanning densitometry of the gel with NIH Image 1.62.

ICAM-1

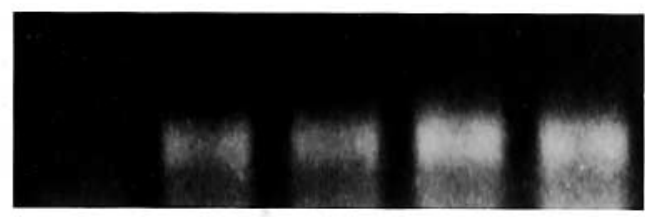

GAPDH

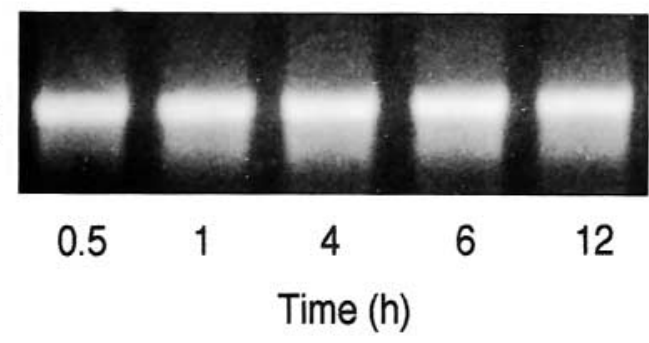

Fig. 2. Time-course analysis of ICAM-1 gene expression induced from KB cells by E. corrodens 1073 stimulation. RNA was isolated from $\mathrm{KB}$ cells after exposure to bacterial stimulation for $0.5,1,4,6$ or $12 \mathrm{~h}$. cDNA synthesis and RT-PCR were performed as described in Materials and methods. The GAPDH housekeeping gene was used as a control. The amounts of ICAM-1 mRNA, compared with those of GAPDH mRNA in the controls, were semi-quantified by scanning densitometry of the gel with NIH Image 1.62.

infection with E. corrodens and continued over the 12-h study period.

\section{Effect of E. corrodens on surface ICAM-1 expression by $K B$ cells}

To determine whether the enhanced expression of ICAM-1 mRNA in KB cells was associated with the increased expression of surface expression of ICAM-1, the effects of $E$. corrodens on the expression of ICAM1 on $\mathrm{KB}$ cell surfaces were examined by cell-based
ELISA and flow cytometry. KB cells were incubated with E. corrodens 1073 for $10 \mathrm{~h}$ and the expression levels of ICAM-1 on cell surfaces were measured by cell-based ELISA. Although surface ICAM-1 levels were little increased in the absence of E. corrodens infection, IFN- $\gamma$ increased the expression of surface ICAM-1 on KB cells by two-fold compared with the uninfected controls (Fig. 3a). After infection of KB cells by E. corrodens 1073, the expression of surface ICAM-1 levels on KB cells was significantly upregulated by $45 \%$ compared with non-stimulated cells (control) (Fig. 3a).

Monolayers of $\mathrm{KB}$ cells were co-cultured with $E$. corrodens 1073 for $10 \mathrm{~h}$ and the quantitative expression of ICAM-1 on KB cells was determined by flow cytometry. In the absence of bacteria (control), the KB cells were found to constitutively express low levels of ICAM-1; the expression of surface ICAM-1 levels on $\mathrm{KB}$ cells was markedly increased compared with the controls (Fig. 3b). The distribution of ICAM-1 expression by $\mathrm{KB}$ cells following infection with E. corrodens 1073 was unimodal and narrow as judged by flow cytometry. This suggests that KB cells are uniform in their potential for up-regulation of cell surface ICAM-1 expression in response to E. corrodens 1073.

\section{Surface ICAM-1 expression and neutrophil adhesion to E. corrodens-infected $K B$ cells}

The possibility that ICAM-1 expressed on KB cells enhanced the binding of neutrophils to KB cells was then tested. In the absence of bacteria (control), the binding of neutrophils to KB cells was little increased but IFN- $\gamma$ significantly increased the binding of neutrophils to $\mathrm{KB}$ cells by two-fold compared with the controls. After the infection of KB cells by $E$. 

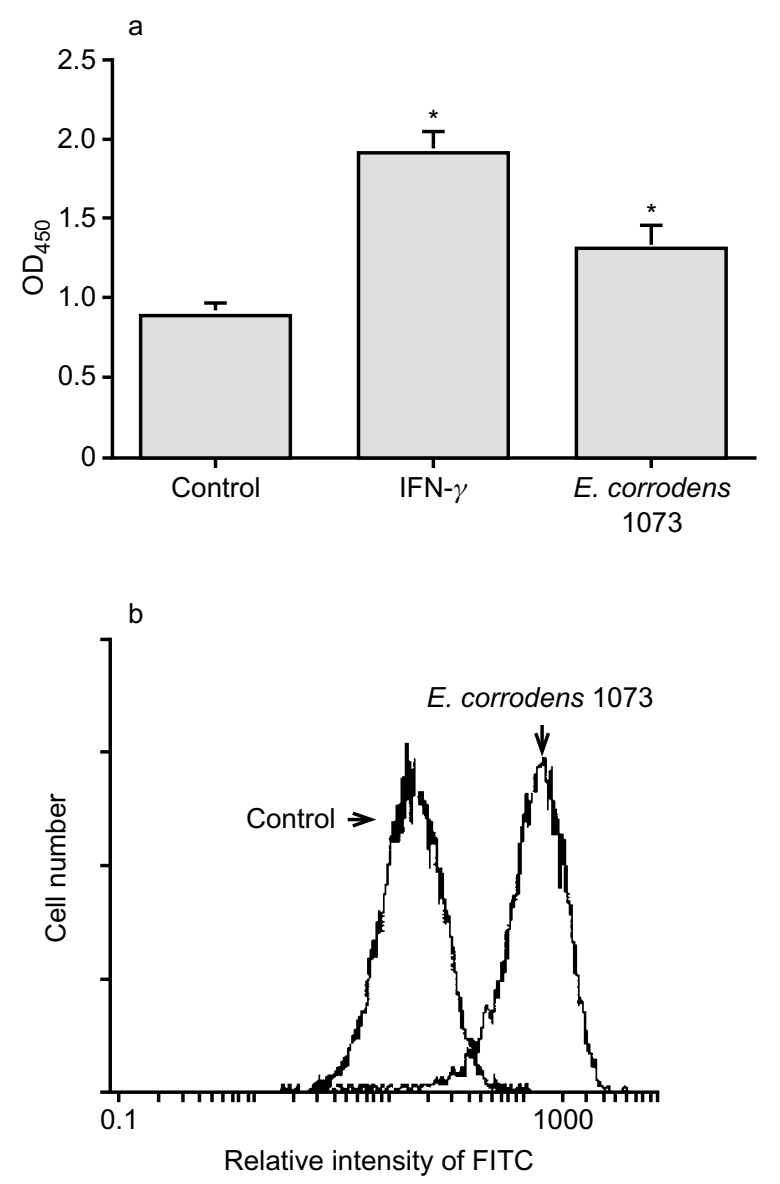

Fig. 3. Surface ICAM-1 expression on $\mathrm{KB}$ cells following infection with $E$. corrodens. Confluent monolayers of $\mathrm{KB}$ cells cultured in 24- or 96-well plates were cultured with E. corrodens for $10 \mathrm{~h}$. ICAM-1 expression on cell surfaces was measured by cell-based ELISA (a) and flow cytometry (b) as described in Materials and methods. Representative findings are shown as the means and SD from three independent experiments. ${ }^{*}$ Significant difference $(p<0.001)$ versus control values.

corrodens 1073, the binding of neutrophils to KB cells was significantly up-regulated by $45 \%$ compared with non-stimulated cells (control) (Fig. 4).

\section{Effect of GalNAc on expression of ICAM-1 on KB cells after infection with E. corrodens}

Previous work demonstrated that GalNAc inhibited the adhesion of $E$. corrodens to $\mathrm{KB}$ cells and slightly down-regulated the IL-8 and IL-6 mRNAs expressed in $\mathrm{KB}$ cells in response to E. corrodens 1073 [20]. To clarify the mechanism of ICAM-1 expression on KB cells after bacterial stimulation and to test the possibility that EcLS are inducers of ICAM-1 expression, the present study observed the effect of GalNAc on the expression of ICAM-1 on KB cells.

In cell-based ELISA (Fig. 5a) and flow cytometric analysis (Fig. 5b), $50 \mathrm{mM}$ of GalNAc down-regulated the expression of ICAM-1 on KB cells after infection

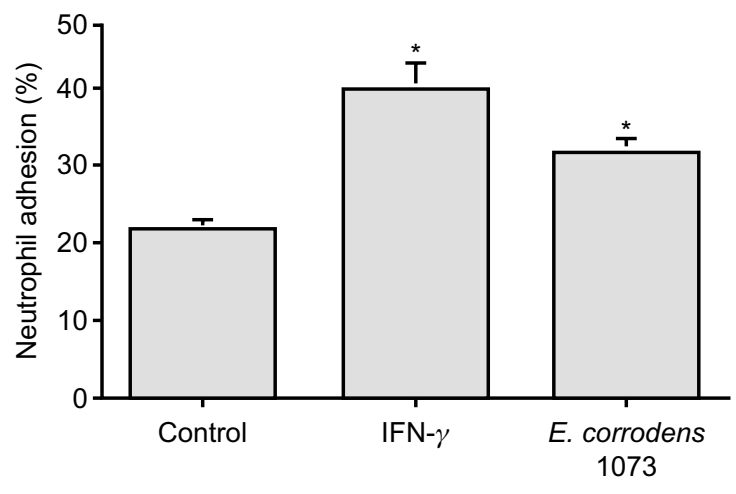

Fig. 4. Neutrophil adhesion assays. KB cell monolayers in 24well plates were incubated with E. corrodens or IFN- $\gamma$ $(40 \mathrm{ng} / \mathrm{ml})$ as described in Materials and methods for $10 \mathrm{~h}$. Then, monolayers were washed and $1 \times 10^{6}$ freshly prepared peripheral blood neutrophils per well were added and allowed to adhere for $30 \mathrm{~min}$ at $37^{\circ} \mathrm{C}$. Total lysates were analysed for myeloperoxidase activity as a measure of the number of neutrophils adhering to monolayers. Neutrophil adherence is expressed as the percentage of adhesive cells compared with $100 \%$ deposited cells. Representative findings are shown as the means and SD from three independent experiments. ${ }^{*}$ Signifignificant differences $(\mathrm{p}<0.001)$ versus control values.

with E. corrodens 1073 to the control level (Fig. 5c). Moreover, adhesion of neutrophils to KB cells infected with E. corrodens 1073 was inhibited to the control level. These findings strongly suggest that EcLS may play an important role in the expression of ICAM-1 on KB cells after infection with E. corrodens 1073.

\section{Effect of EcLS on expression of ICAM-1 mRNA and surface ICAM-1 on KB cells}

To confirm the role of EcLS in the expression of ICAM-1 induced by E. corrodens 1073, the present study determined whether EcLS could increase the expression of ICAM-1 on KB cells. In RT-PCR, EcLS enhanced the expression of ICAM-1 mRNA in a dosedependent manner and the addition of GalNAc completely abolished the expression of ICAM-1 mRNA (Fig. 6). In cell-based ELISA and flow cytometric analysis, EcLS increased the expression of surface ICAM-1 on KB cells to levels equivalent with that of E. corrodens whole cells and the addition of GalNAc to the culture mixture reduced the increase of surface ICAM-1 expression to the control level (Fig. 7a and b). In neutrophil adhesion assays, EcLS increased the binding of neutrophils to KB cells and the addition of GalNAc to the culture mixtures also decreased the adherence of neutrophils to the control level (Fig. 7c). These findings appeared to be similar to those observed in experiments with E. corrodens whole cells. Taken together, these findings suggest that EcLS may be the crucial factor that induces the expression of ICAM-1 expression on gingival epithelial cells infected with $E$. corrodens. 

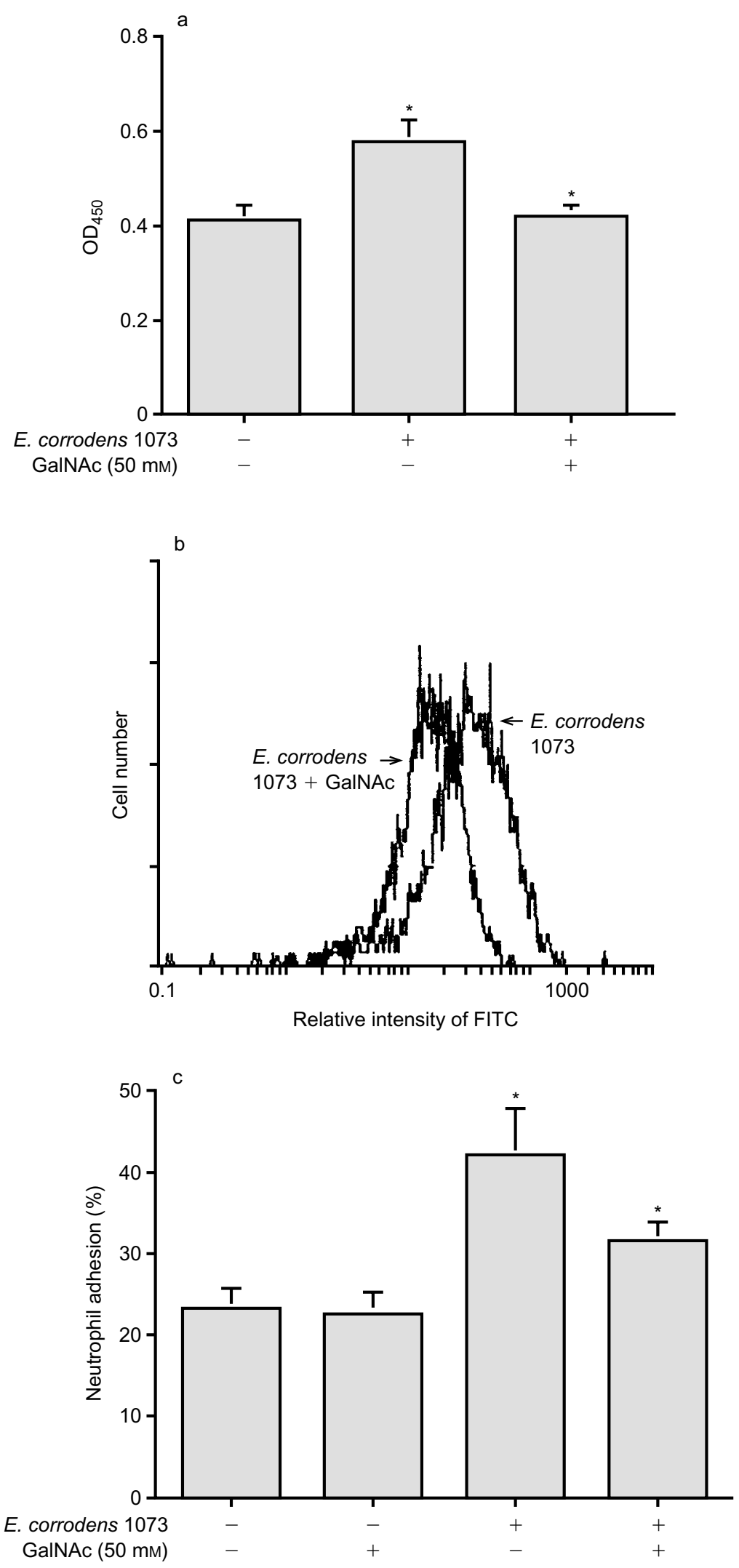

Fig. 5. Inhibitory effects of GalNAc on the expression of ICAM-1 by KB cells following infection with E. corrodens 1073 . KB cell monolayers in 24- or 96-well plates were cultured with E. corrodens 1073 in the presence or absence of GalNAc (50 mM) for $10 \mathrm{~h}$. (a) ICAM-1 expression levels on the cell surfaces were measured by cell-based ELISA as described in Materials and methods. Representative findings are shown as the means and SD from three independent experiments. (b) Cell suspensions were then prepared and were labelled for $30 \mathrm{~min}$ at $4^{\circ} \mathrm{C}$ with FITC-conjugated anti-human ICAM-1 MAb and analysed by flow cytometry as described in Materials and methods. (c) KB cell monolayers in 24-well plates were cultured with E. corrodens 1073 with or without GalNAc $(50 \mathrm{mM})$ for $10 \mathrm{~h}$. Neutrophil adherence is expressed as the percentage of adhesive cells compared with $100 \%$ deposited cells. Representative findings are shown as the means and SD from three independent experiments. ${ }^{*}$ Significant differences $(\mathrm{p}<0.001)$ versus control values. 


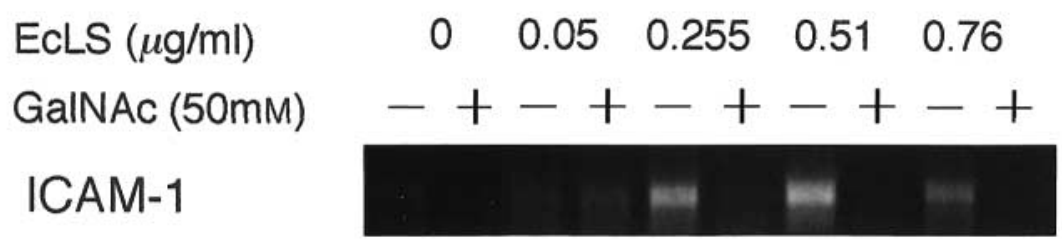

Fig. 6. Induction of the expression of ICAM-1 mRNA on KB cells stimulated with EcLS. KB cells were incubated with the indicated concentration of EcLS for $10 \mathrm{~h}$ in the presence or absence of GalNAc $(50 \mathrm{mM})$. cDNA synthesis and RT-PCR were performed as described in Materials and methods.

\section{Discussion}

Neutrophils within the gingival crevice provide the first cellular host defence mechanism against periodontopathic bacteria [1]. Half the leucocytes infiltrating junctional epithelium and $90 \%$ of the leucocytes isolated from crevicular fluid are neutrophils [24, 25]. The concentration of neutrophils in the periodontal tissues exceeds the concentration of neutrophils in blood [1]. Thus, it has been suggested that neutrophils play important roles in the establishment of periodontal lesions. While the complex events related to transendothelial migration of neutrophils are being widely addressed, those related to transepithelial migration have received less attention. However, such transepithelial migration of neutrophils may be clinically important in the establishment of periodontal lesions [26].

Tonetti et al. reported that neutrophil access into the junctional epithelium was not random but rather a highly regulated process able to selectively enrich neutrophils, and the establishment of a gradient of ICAM-1 expression across the junctional epithelium and the expression of IL-8 in its superficial layers probably represent important regulatory mechanisms leading to neutrophil migration into the gingival sulcus [3].

To elucidate those regulatory processes for neutrophil migration into the gingival tissue a recent study demonstrated that $E$. corrodens surface proteins and products secreted into the culture supernate are able to activate the epithelial cells to secrete pro-inflammatory cytokines, such as IL-6 and IL-8, which are a prerequisite for transmigration and accumulation of neutrophils into gingival epithelium and crevices [20]. The findings of the present report demonstrate that $\mathrm{KB}$ cells up-regulate both the expression of ICAM-1 mRNA (Fig. 1) and the expression of membrane ICAM-1 (Fig. 3) in response to E. corrodens infection. Moreover, the expression of ICAM-1 in response to $E$. corrodens infection of primary cultures of gingival epithelial cells appeared to be very similar to that observed in experiments with $\mathrm{KB}$ cells (data not shown). Taken together, these findings suggest that $E$. corrodens appears to be capable of establishing of a gradient of ICAM-1 and IL-8 expression across the junctional epithelium.
A previous study with cell-free E. corrodens culture supernates demonstrated that the direct contact of $E$. corrodens 1073 with oral epithelial cells was not necessarily required for the stimulation of IL- 6 and IL8 secretion [20]. In contrast, cell-free E. corrodens culture supernates did not increase the expression of ICAM-1. This finding suggests that the activation of ICAM-1 expression in gingival epithelial cells may require the direct contact of E. corrodens cells and gingival epithelial cells. Therefore, the present study aimed to determine whether EcLS, which was a GalNAc-specific lectin-like adhesin of E. corrodens, played a crucial role in the expression of ICAM-1 on KB cells. As expected GalNAc, which competitively inhibited adhesion of E. corrodens to epithelial cells mediated by EcLS [15], reduced the expression of ICAM-1 on KB cells by infection with $E$. corrodens (Fig. 5a and b). This finding strongly indicated the involvement of EcLS in the expression of ICAM-1 on $\mathrm{KB}$ cells infected with E. corrodens. To further confirm the involvement of EcLS, the study determined whether purified EcLS increased the present expression of ICAM-1 on KB cells. EcLS increased the expression of ICAM-1 mRNA (Fig. 6), cell surface ICAM-1 expression on $\mathrm{KB}$ cells (Fig. 7a and b) and neutrophil adhesion (Fig. 7c). These findings confirm that EcLS plays a crucial role in the expression of ICAM-1 on KB cells infected with E. corrodens. Eckmann et al. [27] reported that galactose/GalNAc-specific lectin of Entamoeba histolytica increased the expression of inflammatory cytokines by cultured human epithelial cells. Therefore, the present study determined whether EcLS was the key factor in the expression of IL-8 by epithelial cells infected with $E$. corrodens. In contrast to expectation, EcLS increased neither the expression of IL-8 mRNA nor the secretion of IL-8 protein by KB cells (data not shown). Therefore, this is the first study to report that bacterial lectin enhanced the expression of ICAM-1 on epithelial cells but did not increase IL-8.

In previous experiments, E. corrodens whole cells slightly induced the expression of TNF- $\alpha$ on KB cells but did not increase IL- $1 \beta$. As the expression of ICAM-1 on epithelial cells is known to be up-regulated by pro-inflammatory cytokines including IL-1 $\beta$ and TNF- $\alpha$ [28-31], the present study determined whether EcLS could induce the production of TNF- $\alpha$ from epithelial cells and whether TNF- $\alpha$ secreted from epithelial cells infected with $E$. corrodens might 

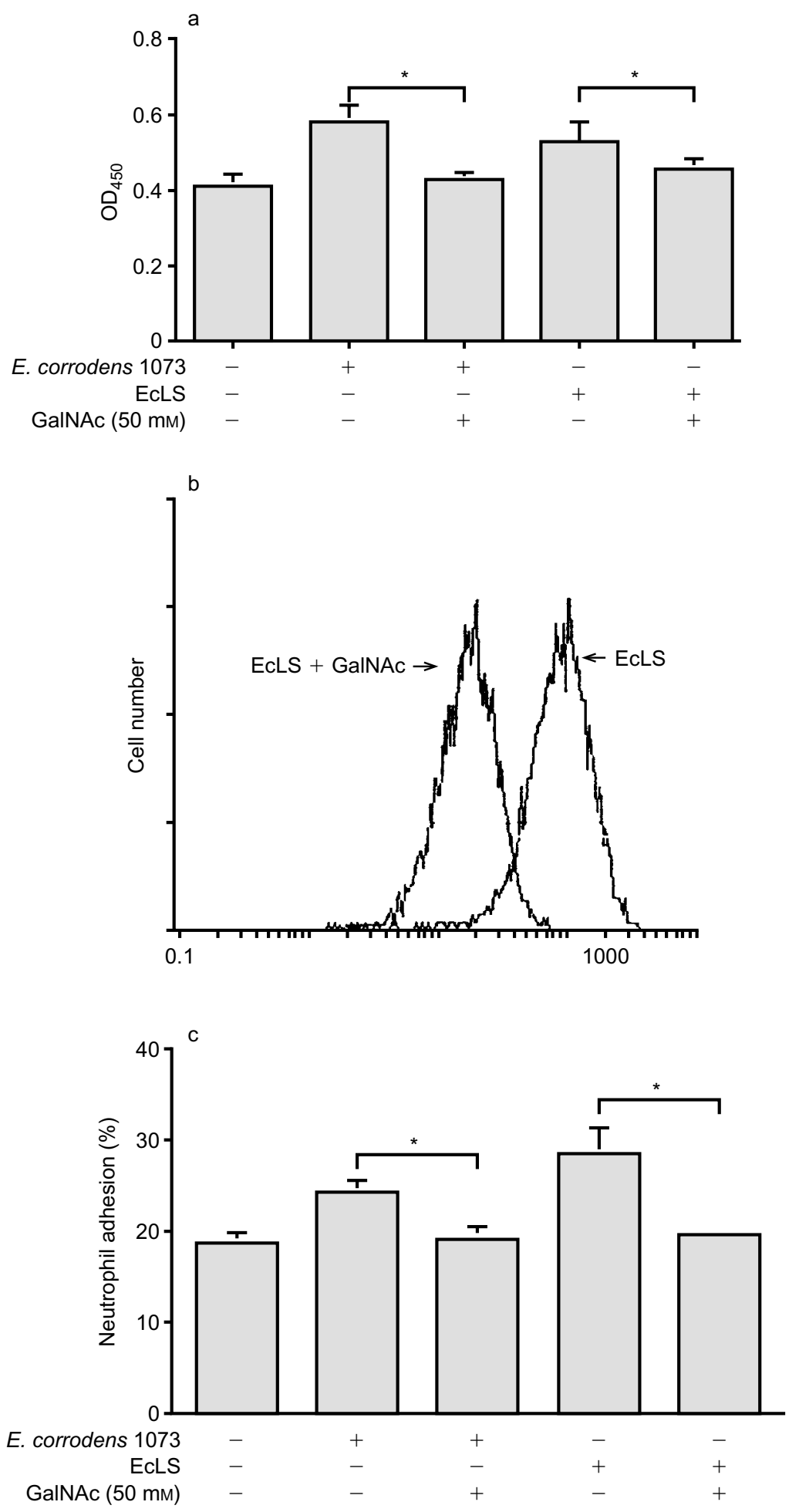

Fig. 7. Enhancement of the expression of surface ICAM-1 and neutrophil adherence on KB cells stimulated with EcLS. KB cell monolayers in 24-well plates were cultured with EcLS $(0.8 \mu \mathrm{g} / \mathrm{ml})$ with or without GalNAc (50 mM) for $10 \mathrm{~h}$. (a) ICAM-1 expression on the cell surfaces was measured by cell-based ELISA. Representative findings are shown as the means and SD from three independent experiments. (b) Cell suspensions were prepared and then ICAM-1 levels on harvested cells were measured by flow cytometry as described in Materials and methods. (c) Neutrophil adherence is expressed as the percentage of adhesive cells compared with $100 \%$ deposited cells. Representative findings are shown as the means and SD from three independent experiments. * Significant differences $(\mathrm{p}<0.001)$ versus control values.

participate in the expression of ICAM-1. In RT-PCR, EcLS did not induce IL- $1 \beta$ or TNF- $\alpha$ in KB cells (data not shown). This finding suggests that EcLS may directly increase the expression of ICAM-1 on gingival epithelial cells but not by mediating the production of TNF- $\alpha$ from gingival epithelial cells.

In a variety of inflammatory and immune disorders, 
including periodontitis, it has been reported that levels of ICAM-1 in body fluids correlate with the intensity of the clinical condition [32-34]. Schmal et al. [35] reported that SICAM-1 enhanced production of MIP-2 and TNF- $\alpha$ by macrophages and intensified lung injury after intrapulmonary disposition of immune complexes. In periodontal tissues, as in lung tissues, sICAM-1 might play an important role in tissue destruction but little is known about the mechanisms of the destruction of the periodontal tissues via sICAM-1. Several studies reported that in crevicular fluid, sICAM-1 levels were higher for patients with inflammation, and the elevated sICAM-1 levels in crevicular fluid may represent increased shedding of this molecule in the interstitial fluid as a result of membrane-bound ICAM-1 upregulation on ICAM-1 gingival-bearing cells in relation to plaque accumulation and inflammation [36-38]. Therefore, the present study examined whether infection of KB cells by E. corrodens increased sICAM-1 levels in culture supernate. In contrast to expectations, E. corrodens was not able to increase the level of sICAM-1 in the culture supernates. Jarvis et al. [39] reported that Neisseria gonorrhoeae could up-regulate the expression of ICAM-1 on epithelial cells but did not enhance the SICAM-1 in culture medium. To shed membrane-bound ICAM-1, certain proteinases might be required.

In conclusion, the findings of the present study demonstrated that EcLS from E. corrodens, GalNAc adherence lectin, directly induces up-regulation of bioactive ICAM-1 expression on gingival epithelial cells and promotes adhesion of neutrophils to epithelial cells. The exact nature of the gingival epithelial cell receptor that is implicated in the activation remains unknown and further investigations will be necessary to characterise more precisely the different molecules involved in the signalling pathway.

We thank T. Okamoto (Hiroshima University School of Dentistry) for supplying KB cells. This work was supported in part by a Grant-in Aid for Scientific Research (10671968) from the Ministry of Education, Culture, Sports, Science and Technology of Japan.

\section{References}

1. Miyasaki KT. The neutrophil: mechanisms of controlling periodontal bacteria. J Periodontol 1991; 62: 761-774.

2. Page RC. Milestones in periodontal research and the remaining critical issues. J Periodontal Res 1999; 34: 331-339.

3. Tonetti MS, Imboden MA, Lang NP. Neutrophil migration into the gingival sulcus is associated with transepithelial gradients of interleukin-8 and ICAM-1. J Periodontol 1998; 69: 1139-1147.

4. Crawford JM, Hopp B. Junctional epithelium expresses the intercellular adhesion molecule ICAM-1. J Periodontal Res 1990; 25: 254-256.

5. Crawford JM. Distribution of ICAM-1, LFA-3 and HLA-DR in healthy and diseased gingival tissues. J Periodontal Res 1992; 27: $291-298$.

6. Gemmell E, Walsh LJ, Savage NW, Seymour GJ. Adhesion molecule expression in chronic inflammatory periodontal disease tissue. J Periodontal Res 1994; 29: 46-53.

7. Moughal NA, Adonogianaki E, Thornhill MH, Kinane DF. Endothelial cell leukocyte adhesion molecule-1 (ELAM-1) and intercellular adhesion molecule-1 (ICAM-1) expression in gingival tissue during health and experimentally-induced gingivitis. J Periodontal Res 1992; 27: 623-630.

8. Chen CK, Wilson ME. Eikenella corrodens in human oral and non-oral infections: a review. $J$ Periodontol 1992; 63: 941-953.

9. Crawford ACR, Socransky SS, Smith E, Phillips R. Pathogenicity testing of oral isolates in gnotobiotic rats. $J$ Dent Res 1977; 56: B120.

10. Slots J. The predominant cultivable microflora of advanced periodontitis. Scand J Dent Res 1977; 85: 114-121.

11. Socransky SS. Microbiology of periodontal disease - present status and future considerations. J Periodontol 1977; 48: 497-504.

12. Ebisu S, Okada H. Agglutination of human erythrocytes by Eikenella corrodens. FEMS Microbiol Lett 1983; 18:153-156.

13. Ebisu S, Nakae H, Okada H. Coaggregation of Eikenella corrodens with oral bacteria mediated by bacterial lectin-like substance. Adv Dent Res 1988; 2: 323-327.

14. Miki Y, Ebisu S, Okada H. The adherence of Eikenella corrodens to guinea pig macrophages in the absence and presence of anti-bacterial antibodies. J Periodontal Res 1987; 22: $359-365$.

15. Yamazaki Y, Ebisu S, Okada H. Eikenella corrodens adherence to human buccal epithelial cells. Infect Immun 1981; 31: 21-27.

16. Yamazaki Y, Ebisu S, Okada H. Partial purification of a bacterial lectinlike substance from Eikenella corrodens. Infect Immun 1988; 56: 191-196.

17. Nakae H, Yumoto H, Matsuo T, Ebisu S. Mitogenic stimulation of murine B lymphocytes by $N$-acetyl-D-galactosamine specific bacterial lectin-like substance from Eikenella corrodens. FEMS Microbiol Lett 1994; 116: 349-353.

18. Azakami $H$, Yumoto $H$, Nakae $H$, Matsuo $T$, Ebisu $S$. Molecular analysis of the gene encoding a protein component of the Eikenella corrodens adhesin complex that is close to the carbohydrate recognition domain. Gene 1996; 180: 207-212.

19. Yumoto H, Azagami H, Nakae H, Matsuo T, Ebisu S. Cloning, sequencing and expression of an Eikenella corrodens gene encoding a component protein of the lectin-like adhesin complex. Gene 1996; 183: 115-121.

20. Yumoto $H$, Nakae $H$, Fujinaka $K$, Ebisu $S$, Matsuo $T$. Interleukin-6 (IL-6) and IL-8 are induced in human oral epithelial cells in response to exposure to periodontopathic Eikenella corrodens. Infect Immun 1999; 67: 384-394.

21. Yumoto H, Nakae H, Yamada $\mathrm{M}$ et al. Soluble products from Eikenella corrodens stimulate oral epithelial cells to induce inflammatory mediators. Oral Microbiol Immunol 2001; 16: 296-305.

22. Huang GT, Eckmann L, Savidge TC, Kagnoff MF. Infection of human intestinal epithelial cells with invasive bacteria upregulates apical intercellular adhesion molecule-1 (ICAM-1) expression and neutrophil adhesion. J Clin Invest 1996; 98: $572-583$.

23. Darveau RP, Belton CM, Reife RA, Lamont RJ. Local chemokine paralysis, a novel pathogenic mechanism for Porphyromonas gingivalis. Infect Immun 1998; 66: 1660-1665.

24. Attstrom R. Presence of leukocytes in crevices of healthy and chronically inflamed gingivae. J Periodontal Res 1970; 5: $42-47$.

25. Schroeder HE. Transmigration and infiltration of leukocytes in human junctional epithelium. Helv Odontol Acta 1973; 17: $6-18$.

26. Tonetti MS. Molecular factors associated with compartmentalization of gingival immune responses and transepithelial neutrophil migration. J Periodontal Res 1997; 32: 104-109.

27. Eckmann L, Reed SL, Smith JR, Kagnoff MF. Entamoeba histolytica trophozoites induce an inflammatory cytokine response by cultured human cells through the paracrine action of cytolytically released interleukin-1 $\alpha$. J Clin Invest 1995; 96: 1269-1279.

28. Dustin ML, Singer KH, Tuck DT, Springer TA. Adhesion of T lymphoblasts to epidermal keratinocytes is regulated by interferon gamma and is mediated by intercellular adhesion molecule-1 (ICAM-1). J Exp Med 1988; 167: 1323-1340.

29. Kaiserlian D, Rigal D, Abello J, Revillard JP. Expression, function and regulation of the intercellular adhesion molecule-1 (ICAM-1) on human intestinal epithelial cell lines. Eur $J$ Immunol 1991; 21: 2415-2421. 
30. Kvale D, Krajci P, Brandtzaeg P. Expression and regulation of adhesion molecules ICAM-1 (CD54) and LFA-3 (CD58) in human intestinal epithelial cell lines. Scand J Immunol 1992; 35: $669-676$.

31. Ledebur HC, Parks TP. Transcriptional regulation of the intercellular adhesion molecule-1 gene by inflammatory cytokines in human endothelial cells. Essential roles of a variant NF- $\kappa$ B site and p65 homodimers. J Biol Chem 1995; 270: $933-943$.

32. Budnik A, Grewe M, Gyufko K, Krutmann J. Analysis of the production of soluble ICAM-1 molecules by human cells. Exp Hematol 1996; 24: 352-359.

33. Endo $\mathrm{S}$, Inada $\mathrm{K}$, Kasai $\mathrm{T}$ et al. Levels of soluble adhesion molecules and cytokines in patients with septic multiple organ failure. J Inflamm 1995-1996; 46: 212-219.

34. Gearing AJ, Newman W. Circulating adhesion molecules in disease. Immunol Today 1993; 14: 506-512.

35. Schmal H, Czermak BJ, Lentsch AB et al. Soluble ICAM-1 activates lung macrophages and enhances lung injury. J Immunol 1998; 161: 3685-3693.

36. Koundouros E, Odell E, Coward P, Wilson R, Palmer RM Soluble adhesion molecules in serum of smokers and nonsmokers, with and without periodontitis. J Periodontal Res 1996; 31: 596-599.

37. Mole N, Kennel de March A, Martin G, Miller N, Bene MC, Faure GC. High levels of soluble intercellular adhesion molecule-1 (ICAM-1) in crevicular fluid of periodontitis patients with plaque. J Clin Periodontol 1998; 25: 754-758.

38. Palmer RM, Scott DA, Meekin TN, Poston RN, Odell EW, Wilson RF. Potential mechanisms of susceptibility to periodontitis in tobacco smokers. J Periodontal Res 1999; 34: $363-369$.

39. Jarvis GA, Li J, Swanson KV. Invasion of human mucosal epithelial cells by Neisseria gonorrhoeae upregulates expression of intercellular adhesion molecule 1 (ICAM-1). Infect Immun 1999; 67: 1149-1156. 